\title{
Feedback System in Healthcare: The Why, What and How
}

\author{
Naveen R. Gowda ${ }^{1}$, Abhinav Wankar ${ }^{1}$, Sanjay Kumar Arya ${ }^{1}$, Vikas H. ${ }^{1}$, Nayana Kollalackal Narayanan ${ }^{2}$ \& C. P. \\ Linto $^{2}$ \\ ${ }^{1}$ Department of Hospital Administration, AIIMS, New Delhi, India \\ ${ }^{2}$ Nursing Officer, AIIMS, New Delhi, India \\ Correspondence: Abhinav Wankar, Senior Resident, Room No 2, Department of Hospital Administration, \\ AIIMS, Ansari Nagar, 110029, New Delhi, India. E-mail: abhinav.wankar@gmail.com
}

\author{
Received: January 18, 2020 Accepted: February 20, $2020 \quad$ Online Published: February 24, 2020 \\ doi:10.5539/ijms.v12n1p52 URL: https://doi.org/10.5539/ijms.v12n1p52
}

\begin{abstract}
Background: A lively, dynamic and interactive feedback system that can connect all the stakeholders and engage them in a sustainable loop of seamless information flow is quintessential for any organization with significant public interface. It is important to balance the asymmetry in the patient doctor relationship and empower the patients.

Methodology: In this regard, process mapping of existing system was done. Ethnographic methods were used with triangulation of data for validity. Three key bottlenecks were identified; the system to collect feedback, the feedback form itself and the overall mindset about the feedback system. A de novo, systematic approach akin to the PDSA (Plan-Do-Study-Act) steps in quality improvement was adopted to create a new feedback system and its continuous incremental improvements thereon.

Results: Short, attractive form with interactive emoticons graded over a likert scale was created and made accessible through standalone kiosks across the institute. Key attention to ease of access, minimizing the number of clicks, removing human interface and providing SMS/E-mail acknowledgement to feedbacks have all contributed to sustainability of the new system with consistently high turn-out/participation.

Conclusion: Designing a customized, hospital specific feedback system rooted more in the experiences on ground is more sustainable and reliable rather than standardized surveys. The same has been reiterated in literature. They can also be used to assess the impact of new interventions. Robust feedback systems can be envisioned as part of accreditation and continuous quality improvement.
\end{abstract}

Keywords: patient feedback, quality improvement, qualitative methods, ethnographic research, technology, patient satisfaction, dynamic feedback system

\section{Introduction}

Effective feedback system is vital for any organisation to keep up with changing needs with time and improve hospital quality (Murante, 2014). It is especially important for the ones with significant public interface as it helps in grasping the pulse of public opinion. Feedback system involves receiving the inputs, bringing in changes and then assessing the impact through the inputs received from the same system. Direct patient feedback is also the core method for measuring patient experience (Coulter, 2009). In essence, a good feedback system should be a lively, dynamic and interactive that can connect all the stakeholders and engage them in a sustainable loop of seamless information flow.

AIIMS, New Delhi is an institute of National importance and apex centre for medical education and research in India catering to large number of patients every day from a wide range of socio-cultural background. Asymmetry in relationship between patient and health care providers call for a robust feedback system to empower the patients and balance this relationship in the long run (Edwards, 2015).

There is a broad spectrum of the levels of expectation to its sequel of patient satisfaction and no gold standard measurement instrument exists (Edwards, 2015). The stereotypic image of being a government organization and tunnel vision focusing on the huge numbers can often perpetuate communication gaps between the general public and the hospital. It was thus decided to study the existing feedback system and explore options to improve it. 
Hospitals commonly use standardized surveys as they provide administrators with the benefit of allowing for comparison and benchmarking against other institutions. However, such standardized surveys have many limitations and are potentially of limited value to the individual patient and the healthcare providers (Benson, 2014).

In this regard, there was a need to have an in-house feedback system that would suite the unique realities of AIIMS (All India Institute of Medical Sciences), New Delhi like huge volumes, multiple specialties, complex organogram, limited resources, wide spectrum of socio-cultural profile of patients and mind-set of employees.

It was decided to keep the new feedback system separate from the existing grievance redressal system. The focus was on capturing the general perception, new/creative ideas and identifies gaps in the system that are commonly overlooked, yet significant for the patients. In short, the idea was not to "lose the forest for the trees".

Therefore, we started with the hypothesis that a de-novo feedback system that is in sync with the ground realities, with scope for continuous, incremental improvements will have better turnout and will be sustainable.

\section{Methodology}

To revamp our existing feedback system and in turn test our hypothesis, the study was carried out in 3 stages:

1) Process mapping of existing system to collect feedback

2) Ethnographic methods-

Triangulation of data was done to assure validity. The following methods were used;

A. Informal interactions with all stakeholders including patients, their attendants/relatives, nurses, hospital attendants and other ground level staff

B. Inputs from administrative staff including senior nurses, duty officers and officer-in-charge

C. Direct observations

D. Record review of the proceedings of administrative rounds and meetings

3) Continuous incremental improvements/changes through PDSA (Plan-Do-Study-Act)

The details of each stage of our study are as under:

\subsection{Process Mapping of Existing System to Collect Feedback}

The prevailing system for collecting feedback/suggestions was studied. As on June 2016 a printed feedback form was given to patients of private and general wards and suggestion boxes were placed in different locations of the hospital including OPD (Out-patient Department), where suggestions/feedback were to be written on paper and dropped in these boxes. 


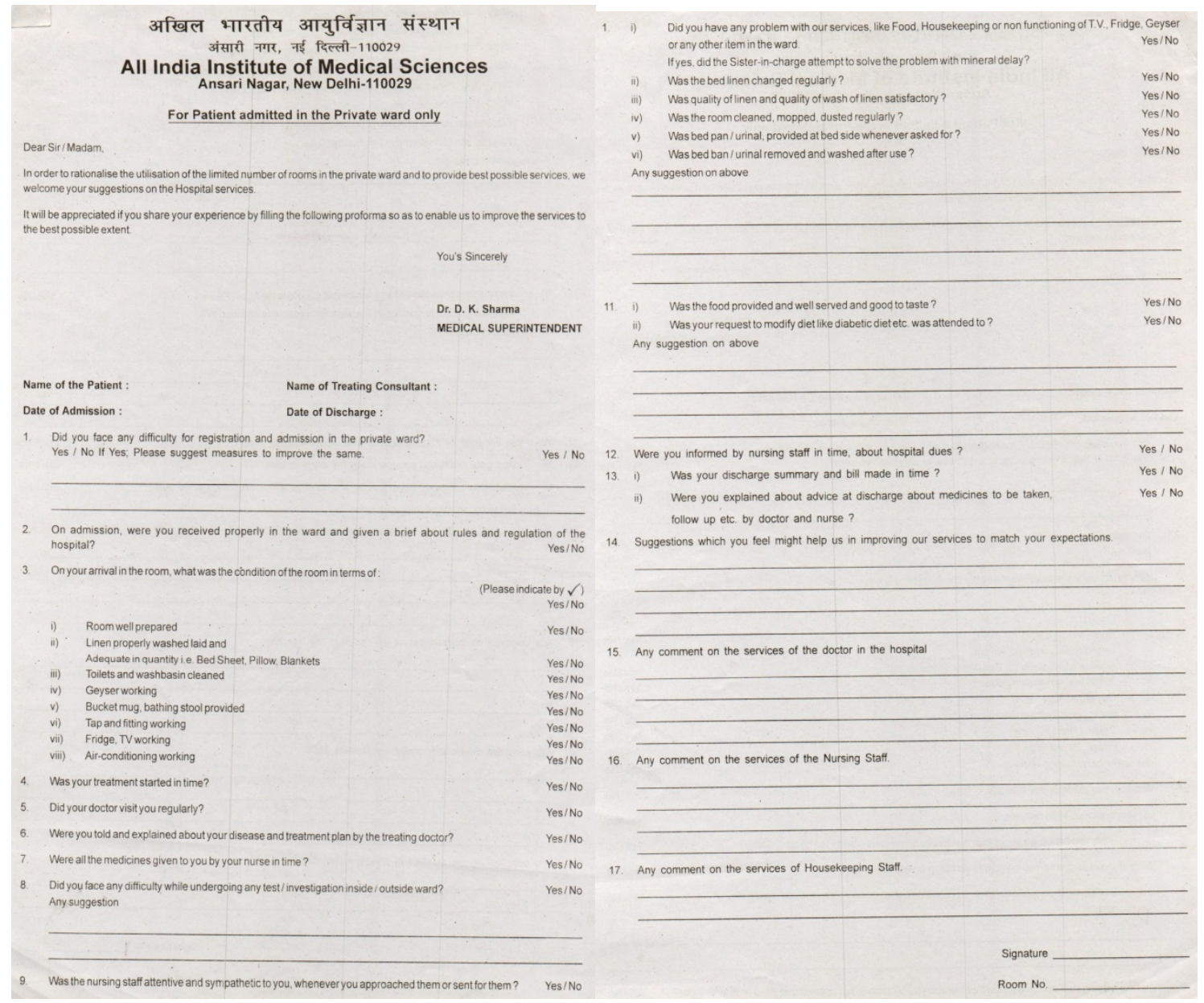

Figure 1. Old feedback form (Printed)

The feedback forms from the private and general wards were often not completely filled and at times reportedly returned unfilled to the nursing staff. The suggestion boxes had logistic constraints and low usage. Overall, the prevailing system had a low turnout and instead was a portal for people to vent their ire making it a second fiddle to the grievance redressal mechanism.

There was no robust mechanism to collect feedback/suggestions and information was in silos across the institute. Thus, the feedback that was being collected was neither broadly representative nor was giving the overall picture. Besides, there was no common portal to collate useful suggestions or creative ideas often given by independent observers from outside the system.

\subsection{Ethnographic Methods}

To get a finer and deeper understanding of the issues with the very design of the feedback system it was decided to use ethnographic methods. These are qualitative, yet provide details that are vital for better understanding of the system under study.

To understand the possible bottlenecks for a robust feedback system informal interactions and direct observations were carried out. The benefit of informal interaction is that interviewees are off guard and chances of confounding factors or biases are lesser. Besides, they could bring out new aspects that were previously not thought of. Participatory approach involving key stakeholders is key to developing an effective feedback system (Cleary, 2014). Therefore, interactions with patients, their attendants and staff members (Nursing staff and Hospital attendants) were carried out and inputs taken.

Direct observations were carried out to understand the prevalent practices and processes involved in the feedback system. Direct observations were first carried out without informing the staff or patients and later observed again after informing them. This approach was also used to assess the user acceptance towards the new feedback form during the stage of repeated iterations. 
The gaps/bottlenecks that were identified broadly belonged to the following three aspects:

\section{A. System to collect feedback:}

The first issue was lack of awareness about the existence of a feedback system among the patients and their attendants. Absence of signboards or any other means of information further deterred people from giving feedback. The nursing staff being the point of contact to collect feedback often avoided voluntarily informing the patients due to apprehension of adverse remarks on themselves.

The feedback form was generally given at the time of discharge when the patients or their attendants are not very keen on filling the feedback form. Also, the suggestion boxes appeared to be in neglected condition with no paper/form around, further decreasing the likelihood of receiving feedbacks.

Therefore, in lines with Digital India mission, it was decided to keep the feedback system completely online, accessible through the web kiosks placed in different patient care areas of the hospital. In order to make it user friendly, due emphasis was laid on minimizing the number of clicks required to submit feedback. In this regard, the system was enabled to automatically import basic patient details linked to UHID (Unique Hospital ID) once it is entered in the form.

\section{B. The feedback form:}

The feedback forms in use were reported to be lengthy and time consuming. Despite touching upon many aspects and being extensive, the form was reported to be less attractive/appealing. Lengthy questions, a mix of objective and descriptive (free text) options and the form appearing cluttered/crowded with words demanded extra attention and effort from the users. This was perceived to be a major obstacle which decreased the turn-out.

Thus, the first challenge was to revamp the feedback form itself to make it more user-friendly. The idea was to design an attractive, short, post card sized, user friendly feedback form which predominantly consisted of pictorial representations and interactive emoticons (Figure 2). The intention was to increase feedback turn out by decreasing the time taken to comprehend and fill the form.

In this regard, common issues were selectively identified based on the inputs from key stake holders like patients, employees, officer-in-charge (Clinical services), as well as deliberation during co-ordination meetings and observations during routine administrative rounds were used. These selective fields were rated along a Likert scale with interactive emoticons to make them attractive and easy to fill. The final version came after multiple revisions of the size, font, colours, spacing, emoticons and symbols/signage based on inputs from patients and their attendants from various wards of the hospital.

Along with the checkboxes a text box for any other open-ended suggestions was provided to crowd-source new innovative ideas (Figure 3). 


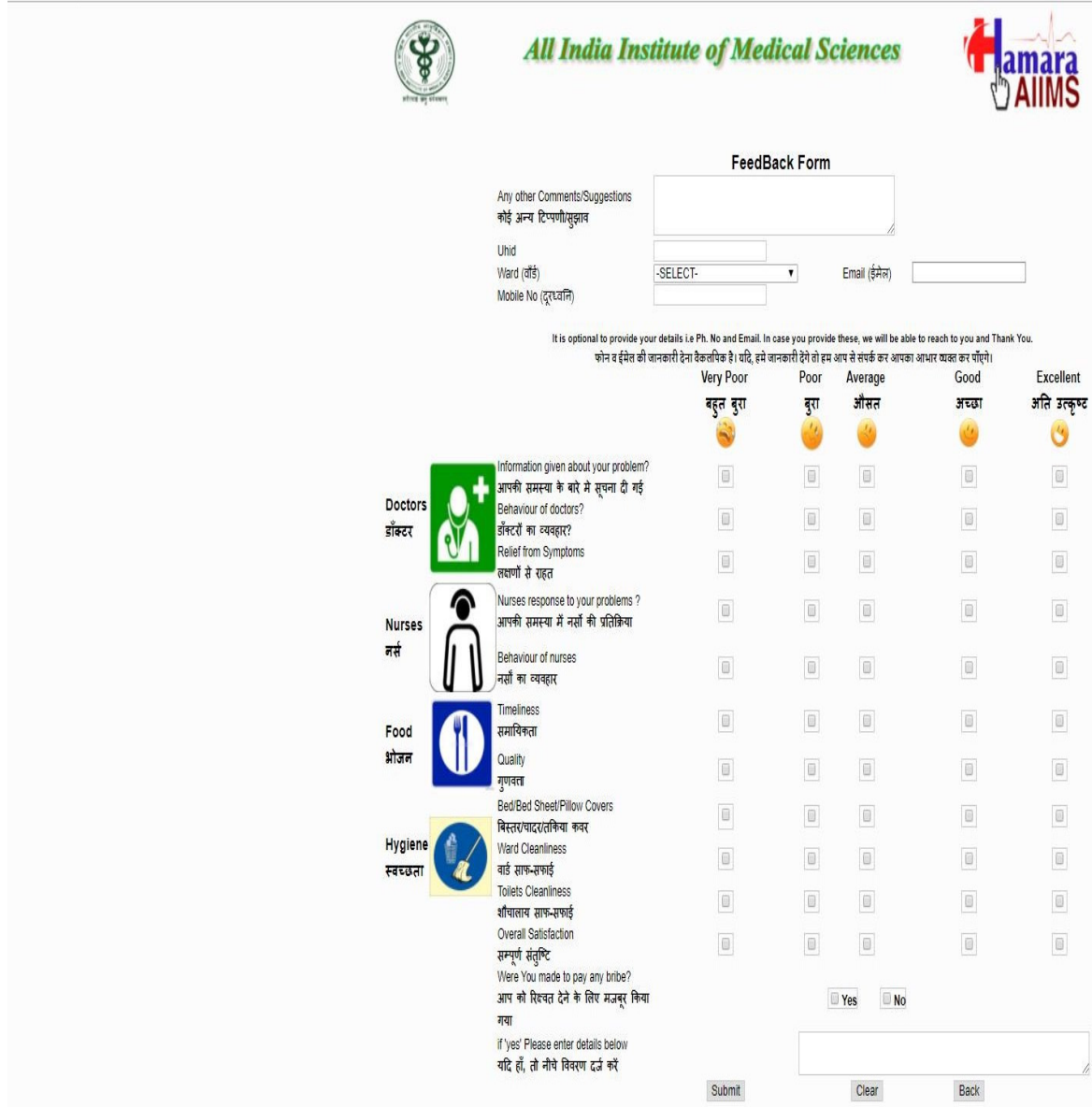

4 type here to search

Figure 2. Revamped feedback form (Online)

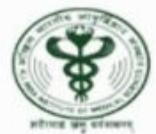

\section{All India Institute of Medical Sciences}

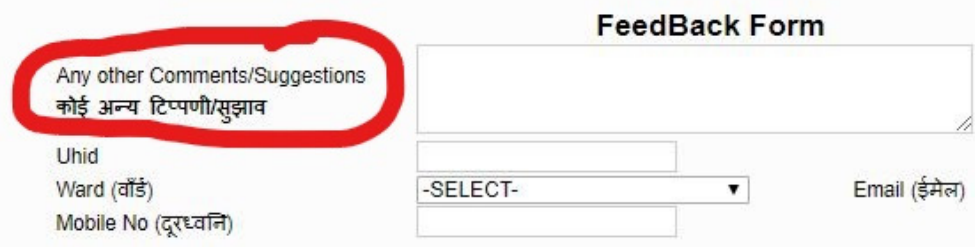

It is optional to provide your details ie Ph. No and Email In case you provide these, we will be able to reach to you and Thank You. फोन व ईमेल की जानकारी देना वेकलपिक है। यदि, हमे जानकारी देंगे तो हम आप से संपर्क कर आपका आभार व्यक्त कर पॉएगे।

$\begin{array}{lllll}\text { Very Poor } & \text { Poor } & \text { Average } & \text { Good } & \text { Excellent } \\ \text { बहुत बुरा } & \text { बुरा } & \text { औसत } & \text { अच्छा } & \text { अति उत्कृष्ट }\end{array}$

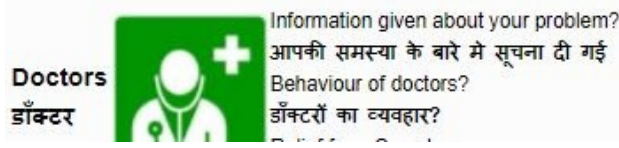

\begin{tabular}{|c|c|c|c|}
\hline$\square$ & $\square$ & $\square$ & $\square$ \\
\hline$\square$ & D & $\square$ & $\square$ \\
\hline
\end{tabular}

Figure 3. Open text box in feedback form 


\section{Mindset-The silent undercurrent:}

i Patients and their attendants/relatives:

Lack of faith in the system with perceived sense of apathy was a major deterrent among patients and their relatives. It was difficult for people to identify with a faceless system. Absence of acknowledgement to feedback furthers the trust gap wherein the patient is unsure whether his feedback was taken note of and feels there is no point in giving one. A perceived conflict of interest while handing over feedback to the employees/staff members creates apprehension of possible retribution towards unfavourable feedback which is yet another hurdle.

New systems run a risk of fizzling out over a period of time. In order to keep the new feedback system sustainable, reinforcing faith among users was found to be paramount. In this regard, a logo and name were designed for the feedback system in order to give it an identity. It creates a perception of an institutionalized, approachable system which can instil more confidence among the users/patients.

One of the main reasons for perceived apathy among the patients was lack of acknowledgement from the hospital to the feedbacks received. A system for providing real time SMS acknowledgement was introduced in order to reinforce the faith of the users/patients in the system.

ii Staff members:

On the other hand, the staff members/employees equate the feedback system to the grievance redressal system. Across the board it is perceived as a threat and fault finding exercise. They were neither keen nor comfortable with feedbacks owing to the scepticism around it.

Keeping the system completely online removed the interface with the employees, which was important to address the perceived sense of conflict of interest among the users/patients. Thus, the other challenge of trust-building and sustainability of the system was addressed.

\subsection{Continuous Incremental Improvements/Changes Through PDSA (Plan-Do-Study-Act)}

A systematic approach akin to the PDSA (Plan-Do-Study-Act) steps in quality improvement was adopted. Each problem statement was delineated, defined and addressed in sync with the other problem statements. PDSA approach was used right from the stage of designing the feedback form. Small incremental changes were done. Eventually, based on inputs from patients a provision for giving anonymous feedback was also introduced. Thus, continuous incremental improvements were done using PDSA approach to keep the system dynamic.

\section{Results}

The new feedback system was made live in February 2017 with the assistance of computer facility. Since this was a de novo initiative, it was decided to start low and go slow for smoother functioning and better learning. This approach has provided time and opportunity to tweak the system, explore pitfalls and learn from the same. 


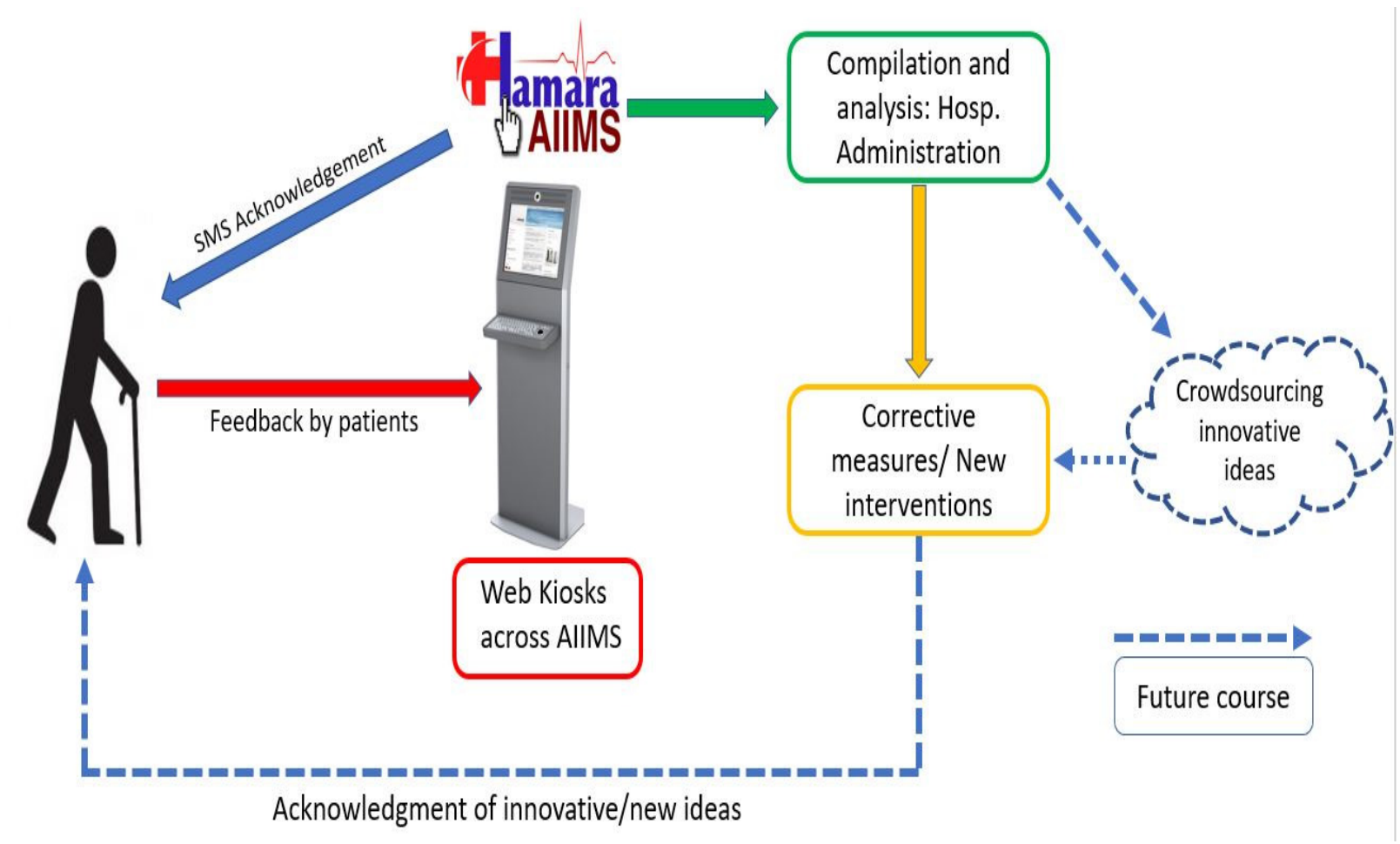

Figure 4. Mechanism of the new feedback system

Therefore, in the first phase the existence of a feedback system has not been widely publicised among patients and yet the turn-out has been consistently improving over the last year, barring few months with network and server issues.

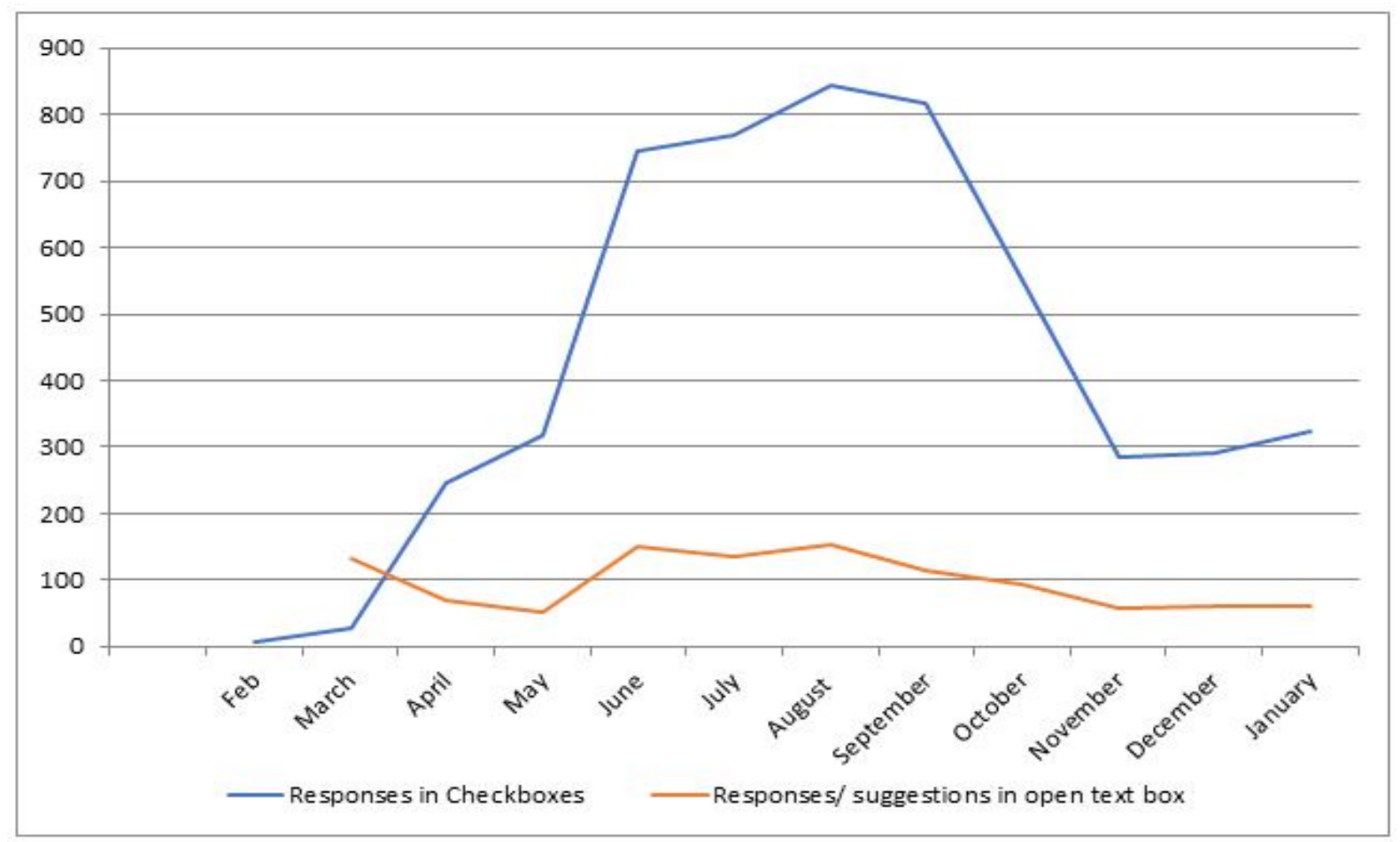

Figure 5. Trends in turn-out through feedback system (Feb'17-Jan'18) 
To start with the suggestion box has been put on the top (above the checkboxes). Based on the most commonly recurring themes in open suggestions, nine broad categories were created. Free texts from the suggestion box were read, interpreted and classified under these nine categories. This is being done by two resident administrators independently to reduce interpretation errors and improve inter-rater reliability. Suggestions received during the respective months which are practical/actionable is being separately tabulated and are under discussion for implementation with higher management.

The data from the checkboxes are being used for longitudinal trend analysis under different domains. This trend has been helpful in assessing the effectiveness of our services over a period time. Turn-out from the new feedback system has been consistent throughout the year, thus indicating that de-novo system in sync with ground realities which undergoes continuous incremental improvements is successful and sustainable.

\section{Discussion}

The existence of online communities such as PatientsLikeMe and HealthTalkOnline suggest that large numbers of the patient population are in fact willing to share their experiences (Basch, 2014). Multiple modes to collect feedback like experience trackers, hand held devices, telephone and online systems, touch screen kiosks among others are being used by hospitals attempting to harness real time data (Brown, 2009).

Multiple approaches including both qualitative and quantitative data are required to enhance the validity (Russell, 2013). Approaches can further be divided into generalizability and the depth of information provided. The Health Foundation contends that these strategies for measuring patient experience are on a continuum(de Silva, 2013).

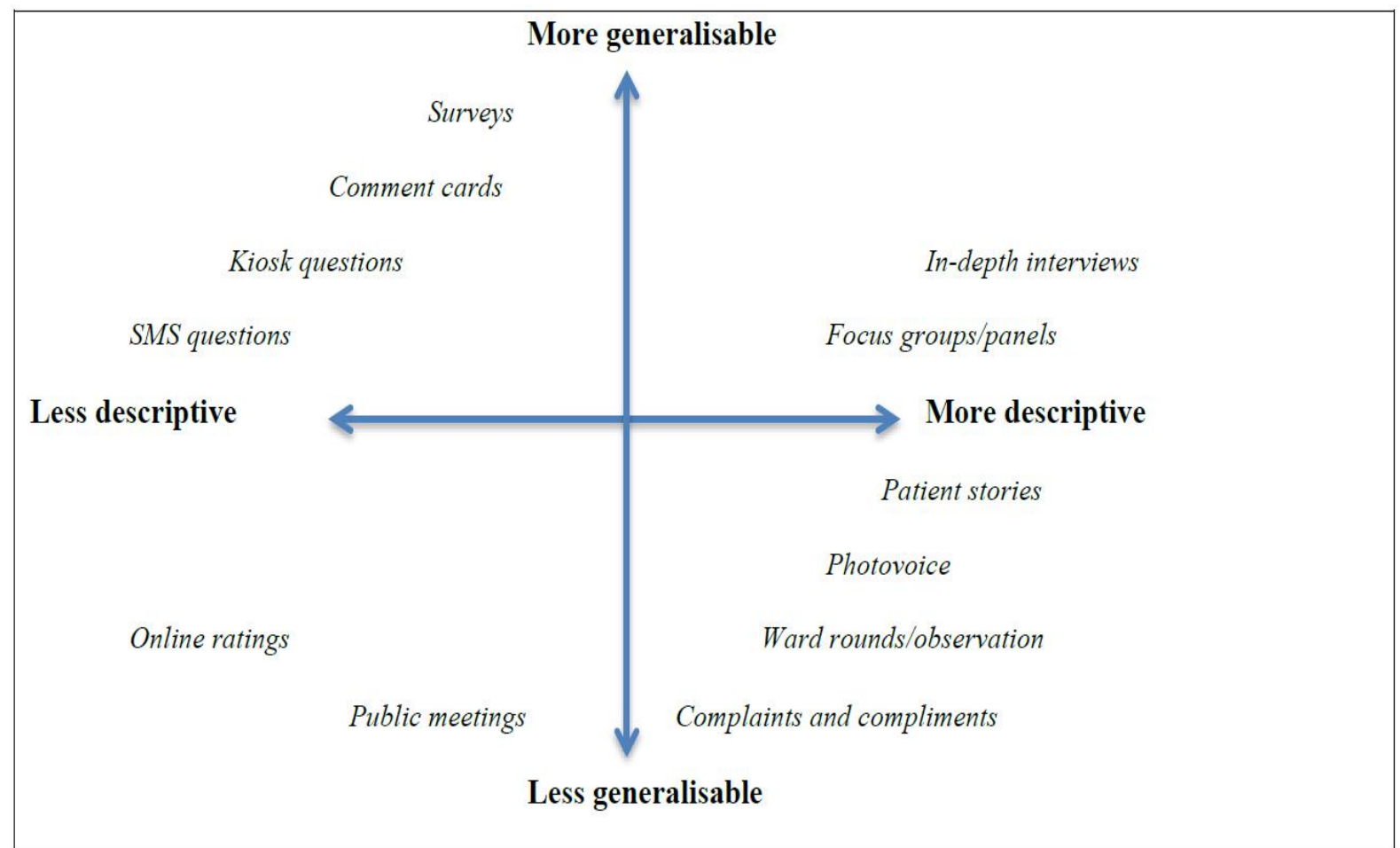

Figure 6. The health foundation (de Silva, 2013), examples of methods used to measure patient experience of health services

In this regard, the focus was on striking a balance between generalizability and descriptiveness keeping in view the practicality of implementation of the new feedback system. Therefore, the new feedback form was made completely online, available on touch screen kiosks containing checkboxes in a Likert scale (quantitative data) and open text box for suggestions (qualitative data).

The solution to obtaining richer data does not lie with lengthier feedback forms. Length of survey can be a deterrent to completion thereby impacting response and value of information (Castle, 2005). Shorter instruments are known to reduce participant burden (Benson, 2014). Besides, the feedback system should preferably include 
items which are under the control of staff and management (Benson, 2014) which are decided through a participatory approach (Cleary, 2014). Fear of jeopardising treatment may alter or even deter patients from giving frank feedback as reiterated by many studies (Russell, 2013; Kalucy, 2009; Delnoij, 2009). Feedback needs to be captured as close to the experience as possible to exclude recall bias (Black, 2009).

McGowan et al. in their paper have demonstrated how PDSA approach can be used for planning, testing, analyzing and refining the feedback system (McGowan, 2018), which is also supported by the findings of our study.

These facts need to be factored in while designing any feedback system. The same were reaffirmed through our approach of informal interactions and direct observations which have been further used while implementing our new feedback system. The first phase included launching, stabilizing and sustaining the feedback system so that it gives real time reflection of the on-ground position. The second phase will build upon this and include interventions as part of Quality improvement initiatives. The new feedback system will provide necessary data to test the effectiveness of the interventions.

\section{Conclusions and Learning}

1) A robust feedback system is essential to capture the pulse of perception amongst the users which is an important factor to improve quality of services.

2) Designing feedback system rooted more in the experiences on ground rather than merely relying on literature is vital to formulate an institute/hospital specific feedback system.

3) Reinforcing the faith of users in the system through due acknowledgement for their feedback is vital in sustaining the system.

4) Feedback system itself has to be dynamic and change with time. This is important to sustain traction among users.

5) Crowd-sourcing innovative ideas/suggestions is vital as the users' perspective might provide new insights which could have gone oversight.

\section{Road ahead:}

1) To further increase participation and response turn-out through the system by widely publicizing and increasing awareness about the system.

2) The consistency in turn-out of responses has provided impetus to use this system as an indirect indicator to evaluate effectiveness of any interventions in the said domains.

3) The feedback system per-se will be continuously evaluated and improved in lines with the PDSA (Plan-Do-Study-Act) steps of quality improvement, in sync with the need of the day.

4) The results and analysis of patient feedback including qualitative information needs to be made available to all stakeholders in as near real time as possible. Staff in particular perceives timely information as having greater validity (Brown, 2009). The leisure industry has been using real time methods to elicit data for a long time however the healthcare industry has been slow to adopt the same (Brown, 2009). Efforts will be made to develop a real time feedback system.

5) Learnings from this exercise can be scaled up for larger initiatives. Government of India's ambitious "Ayushman Bharat Yojana" aims to provide health assurance to almost half the country's population through strategic engagement of private sector through empanelment of selected, accredited hospitals. In this regard, a dynamic feedback system based on machine learning and Artificial Intelligence tools can provide valuable data that could be region, hospital and even patient specific. Such a robust feedback system would be essential for empowering the patients and overall quality improvement in healthcare.

\section{Acknowledgements}

Our special thanks to the Computer Facility, AIIMS New Delhi for helping us smoothly launch and maintain the new feedback system. The Nursing Informatics Specialists (NIS) have also been very helpful during the initial phases. No funding was taken for this study. No conflict of interest to declare.

\section{References}

Basch, E. (2014). New frontiers in patient-reported outcomes: adverse event reporting, comparative effectiveness, and quality assessment. Annual Review of Medicine, 65, 307-317. https://doi.org/10.1146/annurev-med-010713-141500 
Benson, T., \& Potts, H. W. (2014). A short generic patient experience questionnaire: howRwedevelopment and validation. BMC Health Services Research, 14(1), 499. https://doi.org/10.1186/s12913-014-0499-z

Black, N., \& Jenkinson, C. (2009). Measuring patients' experiences and outcomes. BMJ, 339, b2495. https://doi.org/10.1136/bmj.b2495

Brown, H., Davidson, D., \& Ellins, J. (2009). NHS West Midlands Investing for Health Real-time Patient Feedback Project Final Report.

Castle, N. G., Brown, J., Hepner, K. A., \& Hays, R. D. (2005). Review of the literature on survey instruments used to collect data on hospital patients' perceptions of care. Health ServicesResearch, 40(6p2), 1996-2017. https://doi.org/10.1111/j.1475-6773.2005.00475.x

Cleary, M., Escott, P., Horsfall, J., Walter, G., \& Jackson, D. (2014). Qualitative research: the optimal scholarly means of understanding the patient experience. Issues in Mental Health Nursing, 35(11), 902-904. https://doi.org/10.3109/01612840.2014.965619

Coulter, A., Fitzpatrick, R., \& Cornwell, J. (2009). Measures of patients' experience in hospital: purpose, methods and uses (pp. 7-9). London: King's Fund.

de Silva, D. (2013). Measuring patient experience (p. 20). London: The Health Foundation.

Delnoij, D. M. (2009). Measuring patient experiences in Europe: what can we learn from the experiences in the USA and England? The European Journal of Public Health, 19(4), 354-356. https://doi.org/10.1093/eurpub/ckp105

Edwards, K. J., Walker, K., \& Duff, J. (2015). Instruments to measure the inpatient hospital experience: a literature review. Patient Experience Journal, 2(2), 77-85. https://doi.org/10.35680/2372-0247.1088

Kalucy, E. C., Katterl, R., \& Jackson, B. E. (2009). Patient experience of health care performance. PHC RIS Policy Issue Review. Primary Health Care Research \& Information Service, Adelaide.

McGowan, M., \& Reid, B. (2018). Using the Plan, Do, Study, Act cycle to enhance a patient feedback system for older adults. British Journal of Nursing, 27(16), 936-941. https://doi.org/10.12968/bjon.2018.27.16.936

Murante, A. M., Vainieri, M., Rojas, D., \& Nuti, S. (2014). Does feedback influence patient-professional communication? Empirical evidence from Italy. Health Policy, 116(2-3), 273-280. https://doi.org/10.1016/j.healthpol.2014.02.001

Russell, S. (2013). Patients' experiences: top heavy with research. Literature Review, 2013, 1-32.

\section{Copyrights}

Copyright for this article is retained by the author, with first publication rights granted to the journal.

This is an open-access article distributed under the terms and conditions of the Creative Commons Attribution license (http://creativecommons.org/licenses/by/4.0/). 